\title{
Function of the urokinase receptor (CD87) in neutrophil chemotaxis
}

\author{
Margaret R. Gyetko, ${ }^{\star}$ Robert G. Sitrin, ${ }^{\star}$ Jennifer A. Fuller, ${ }^{\star}$ Robert F. Todd III, ${ }^{\dagger}$ Howard Petty, ${ }^{\ddagger}$ \\ and Theodore J. Standiford* \\ *Division of Pulmonary and Critical Care Medicine and ${ }^{\dagger}$ Division of Hematology/Oncology, Department of Internal \\ Medicine, Ann Arbor Veterans Affairs Medical Center and University of Michigan Medical Center, Ann Arbor. \\ Michigan, and $\ddagger$ Department of Biological Sciences, Wayne State University, Detroit, Michigan
}

\begin{abstract}
During recruitment, leukocytes respond to chemotaxins and traverse matrix barriers. Urokinase-type plasminogen activator (uPA), bound to its receptor (uPAR; CD87) facilitates plasmin formation, which promotes matrix proteolysis. Polymorphonuclear leukocytes (PMNs) are critical to the inflammatory response and express both uPA and CD87. To determine whether uPA and CD87 are required for PMN chemotaxis, PMNs were pretreated with an anti-CD87 monoclonal antibody $(\mathrm{mAb})$, a neutralizing anti-uPA mAb, or uPA. PMN chemotaxis was profoundly suppressed by the anti-CD87 $\mathrm{mAb}$ but was unaffected by anti-uPA mAb or uPA. The role CD87 plays in chemotaxis may be related to its ability to associate with $\mathrm{CR3}$. CD87/CR3 coupling can be disrupted by specific saccharides. The same saccharides that disrupt CD87/CR3 coupling (NADG, Dmannose, and mannoside) inhibit PMN chemotaxis. We conclude that $\mathrm{CD87}$ plays a crucial role in $\mathrm{PMN}$ chemotaxis in vitro that is independent of uPA enzyme activity but may be related to the ability of CD87 to interact with CR3. J. Leukoc. Biol. 58: 533-538; 1995.
\end{abstract}

Key Words: cell movement $\cdot$ complement receptor $3 \cdot$ saccharides $\cdot$ integrins

\section{INTRODUCTION}

Recruitment of (PMNs) to inflammatory foci requires that the cells become oriented to a chemotactic gradient and then move through a complex sequence of adhesion, cytoskeletal rearrangement, movement, and detachment steps $[1,2]$. During extravasation into inflammatory sites, cells must also traverse tissue planes, a process for which extracellular proteases may be required to degrade extracellular matrix (ECM) proteins [3-5]. By producing urokinase-type plasminogen activator (uPA) and binding uPA to high-affinity receptors (uPAR; CD87) on the plasma membrane, migrating cells can convert the proenzyme plasminogen to active plasmin and concentrate it in the immediate pericellular environment [6-8]. Plasmin is a protease of broad specificity that can directly or indirectly, through the activation of latent metalloproteinases, degrade ECM proteins and basement membranes $[6,9,10]$. Both uPA and CD87 have been shown to figure importantly in several models of cell invasion [3, 11]. Recent work has linked CD87 more directly to cell movement [12-16]. We have reported that $\mathrm{CD} 87$ clusters to the leading edge of migration on the monocyte cell surface in response to chemotactic signals and that unencumbered CD87 expression is required for monocyte chemotaxis in vitro. Disrupting CD87 function either by monoclonal antibody (mAb) against CD87 or by suppressing CD87 expression with antisense oligonucleotides reduces monocyte chemotaxis to the level seen in random cell movement or chemokinesis [17]. Monocyte chemotaxis is unaffected by receptor-associated uPA activity under matrix-free conditions. This indicates that CD87 is directly involved in cellular locomotion independent of its role in uPA binding and the regulation of pericellular proteolysis.

PMNs and monocytes face similar requirements for responding to chemotaxins and penetrating ECM barriers to reach inflammatory foci. Inasmuch as PMNs express both uPA and CD87 and CD87 translocates to the cell surface in response to formylmethionyl-leucyl-phenylalanine (fMLP) [12], we sought to determine whether CD87 is required for PMN chemotaxis. We demonstrate that functional CD87 is required for PMN chemotaxis under ECM-free conditions, as chemotaxis is substantially reduced by treatment of the cells with anti-CD87 $\mathrm{mAb}$. uPA catalytic activity does not affect PMN chemotaxis under these conditions. Further, we demonstrate that PMN chemotaxis is selectively inhibited by the same profile of saccharides that disrupt the association between CD87 and CR3.

Abbreviations: ECM, extracellular matrix; FL-FNLPNTL, $N$-formylNle-Leu-Phe-Nle-Tyr-Lys; fMLP, formylmethionyl-leucyl-phenylalanine; GPI, glycosylphosphatidylinositol; HBSS, Hanks' balanced salt solution; HMW, high molecular weight; HPF, high-power field; IgCl, immunoglobulin $\mathrm{Gl}$; IL-8, interleukin-8; mAb, monoclonal antibody; NADG, $N$-acetyl-D-glucosamine; PMN, polymorphonuclear leukocyte; uPA, urokinase-type plasminogen activator.

Reprint requests: Margaret R. Gyetko, 3916 Taubman Center, Medical Center Drive, Ann Arbor, MI 48103-0360.

Received May 2, 1995; revised July 19, 1995; accepted July 21, 1995. 


\section{MATERIALS AND METHODS}

\section{Reagents}

High-molecular-weight urokinase (HMW-uPA, catalytically active and capable of binding to CD87) and murine anti-human uPA mAb (catalog number 394, immunoglobulin G1) were obtained from American Diagnostica (Greenwich, CT). This antibody neutralizes uPA catalytic activity and recognizes free $\mathrm{UPA}$, receptor-bound $\mathrm{uPA}$, and pro-uPA [18]. The mouse anti-human CD87 $\mathrm{mAb}$ (clone 3B10, IgG2a), also designated anti-Mo3f, recognizes an epitope in the CD87 ligand binding region (domain 1) [19]. This antibody, prepared as described previously, was used either as dilutions of ascites or as purified $\operatorname{IgC}(5 \mu \mathrm{g} / \mathrm{ml})[20,21]$. Control mouse IgC2a mAbs were obtained from Southern Biotechnology (Birmingham, AL). N-Acetyl-D-glucosamine (NADG), sorbitol, fructose, $\alpha$-methyl-D-mannoside, and $D$-mannose were obtained from Sigma Chemical Co. (St. Louis, MO). Sucrose was obtained from Spectrum (Redondo Beach, CA). The fluorescein conjugate of $N$-formyl-Nle-LeuPhe-Nle-Tyr-Lys (FL-FNLPNTL) was obtained from Molecular Probes, Eugene, OR.

\section{Isolation of human PMNs}

Heparinized venous blood collected from healthy volunteers was mixed 1:1 with $0.9 \%$ saline and separated from mononuclear cells by FicollHypaque density gradient centrifugation. PMNs were then isolated by sedimentation in $5 \%$ dextran, $0.9 \%$ saline (Sigma Chemical Co.) and the erythrocytes removed by hypotonic lysis. After washing twice, the cells were suspended $\left(4 \times 10^{6}\right.$ cells $\left./ \mathrm{ml}\right)$ in Hanks' balanced salt solution (HBSS) with calcium and magnesium (Gibco, Grand Island, NY).

\section{Chemotaxis assay}

Cells were pretreated with mAbs, exogenous $\mathrm{HMW}$-uPA or saccharides $\left(100 \mathrm{mM}\right.$ ) in azide-free HBSS (Gibco) for $30 \mathrm{~min}$ at $4^{\circ} \mathrm{C}$. PMNs were then loaded $\left(1 \times 10^{6}\right.$ cells/well $)$ into the upper chambers of a multiwell chemotaxis apparatus (Neuro Probe, Cabin John, MD) separated from either $10^{-7} \mathrm{M}$ MLP (Sigma) or $10 \mathrm{ng} / \mathrm{ml}$ recombinant human interleukin 8 (IL-8; R\&D Systems. Minneapolis, MN) by a single $3-\mu \mathrm{m}$ pore, $50 \mathrm{~mm}^{2}$ PVP-free polycarbonate filter, and incubated at $37^{\circ} \mathrm{C}$ for $1 \mathrm{~h}$. The filters were then removed, the upper surface scraped free of cells, fixed in methanol, and stained with toluidine blue. The number of cells migrating through the pores were counted for each condition. All conditions were assayed in duplicate. The number of cells per high-power field (HPF) (10 fields for each condition), minus background (random cell movement), is expressed as a percentage of untreated control cells (no pretreatment, exposed to the chemotactic gradient) unless otherwise indicated. Controls included cells exposed to medium without chemotaxin in either chamber (random cell movement), cells exposed to the chemotaxin in both upper and lower chambers (chemokinesis), and anti-CD87 $\mathrm{mAb}$ in the lower chamber along with the chemotaxin.

\section{Statistics}

Comparisons between groups were performed with one-sample Student's $t$-tests [22]. Data are expressed as mean \pm SEM. Statistical significance was taken to represent a $P$ value $\leq .05$.

\section{RESULTS}

\section{Effects of anti-CD87 and anti-uPA mAbs on PMN chemotaxis}

We sought to determine whether functional CD87 or catalytically active $\mathrm{UPA}$ was required for PMN chemotaxis toward fMLP $\left(10^{-7} \mathrm{M}\right)$. Anti-CD87 and an isotype-matched control murine $\mathrm{mAb}$ (IgG2a) were used at 1:50 dilutions. PMNs were incubated in medium alone or were treated with either anti-CD87 or anti-uPA mAb prior to loading in the upper wells. As shown in Figure 1, incubation with the anti-CD87 mAb dramatically reduced $\mathrm{m} M L P$-induced chemotaxis, to $26.5 \pm 7.9 \%$ of controls $(P<.003)$. In distinct contrast, incubation with a neutralizing anti-uPA $\mathrm{mAb}$ had no effect on neutrophil chemotaxis (102.5 \pm $10.6 \%$ of untreated cells). Moreover, saturating CD87 with exogenous HMW-uPA $(4 \mu \mathrm{g} / \mathrm{ml})$ had no effect on chemotaxis (89.5 $\pm 8.6 \%$ of untreated cells; $P=.3$ ). Treating PMNs with purified intact anti-CD87 $\mathrm{mAb}$ reduced chemotaxis to $15.2 \pm 2.7 \%$ of untreated controls $(P=0.02)$. Further, incubating the PMNs with a control IgG2a mAb had no effect on chemotaxis $(110.5 \pm 8.9 \%$ of untreated controls), arguing against a nonspecific effect induced by exogenous immunoglobulin, as might occur by binding to Fc receptors. We have previously observed that anti-CD87 $F\left(a b^{\prime}\right)_{2}$ fragments had the same suppressive effect on monocyte chemotaxis as purified intact $\mathrm{mAb}$ or dilutions of ascites [17]. We conclude that plasma membrane CD87 is required for PMN chemotaxis in response to fMLP. Moreover, neutrophil chemotaxis is not dependent on the catalytic activity of uPA, nor is it influenced by high concentrations of exogenous uPA.

We next sought to determine whether dependence on CD87 is limited to fMLP-stimulated PMN chemotaxis. The preceding studies were therefore repeated using IL-8 at 10 $\mathrm{ng} / \mathrm{ml}$ as the chemotaxin. As shown in Figure 2, the results using IL-8 were strikingly similar to those obtained with fMLP. Chemotaxis was markedly reduced by incubating the cells with the anti-CD87 $\mathrm{mAb}(32.3 \pm 6.1 \%$ of untreated cells; $P<.002)$. Again, neither treating the cells with anti-uPA mAb nor preincubating the cells with HMW-uPA affected chemotaxis $(102.0 \pm 3.1 \%$ and $93.7 \pm 2.6 \%$ of untreated cells respectively; $P=\mathrm{NS}$ ). Further, incubating the PMNs with a control IgG2a mAb resulted in the same level of chemotaxis $(100.0 \pm 5.7 \%)$ as in untreated controls. Thus, the required role of CD87 in PMN chemotaxis is not

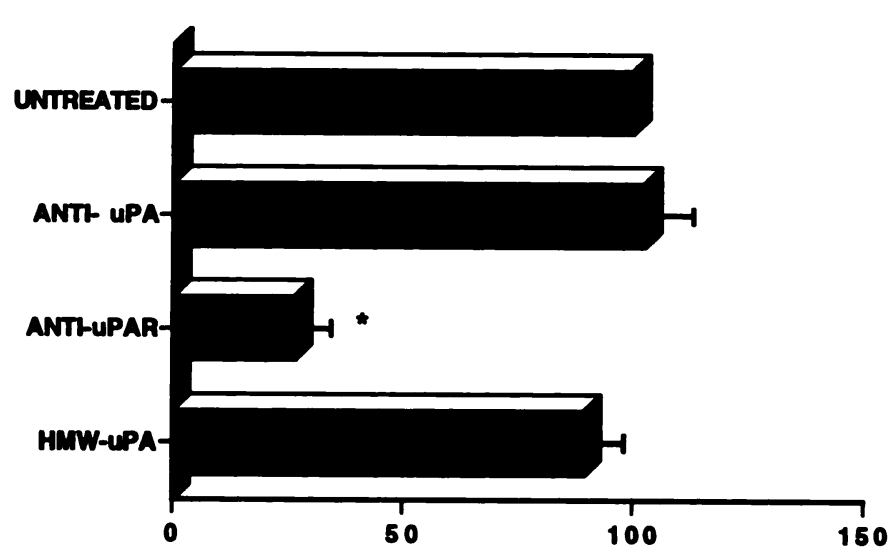

Fig. 1. Suppression of AMLP-induced chemotaxis by anti-CD87 mAb. Data (number of cells/HPF minus background migration) are expressed as a percentage of untreated PMNs. ${ }^{*} P<.003, n=4$. Neither anti-uPA mAb nor addition of uPA significantly affected PMN chemotaxis. Cell counts per high-power field: untreated controls, $65.5 \pm 12.9$; random movement, $9.2 \pm 3.6$. 


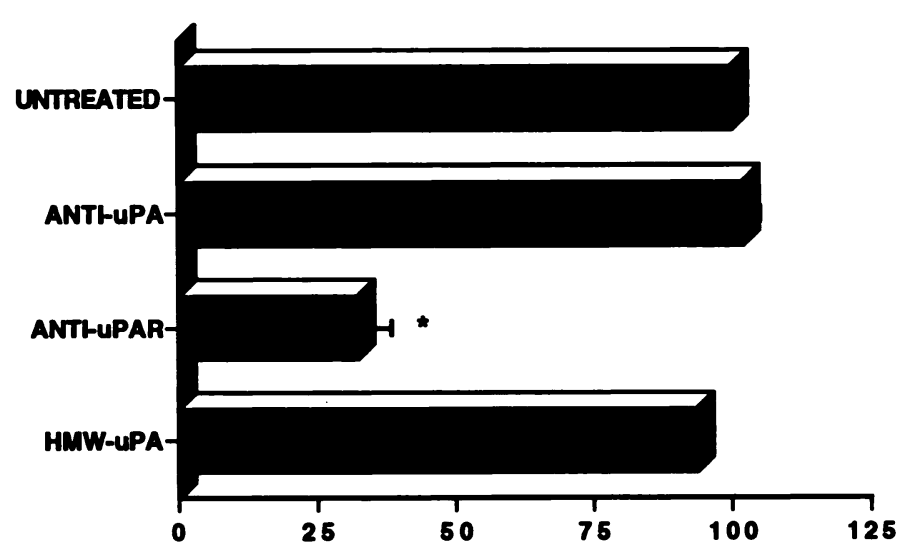

Fig. 2. Suppression of IL-8-induced chemotaxis by anti-CD87 mAb. Data are expressed as in Figure 1. ${ }^{*} P<.002, n=4$. Neither anti-uPA mAb nor addition of $u P A$ significantly affected PMN chemotaxis. Cell counts per high-power field: untreated controls, $72.2 \pm 10.2$; random movement, 9.2 \pm 3.6.

limited to a single chemotaxin but holds equally true for IL-8 and fMLP.

For the preceding experiments, the mAb or HMW-uPA was present in the upper chamber throughout the chemotaxis assay. A recent report indicates that PMNs translocate CD87 from intracellular stores to the plasma membrane in response to fMLP [12]. We reasoned that the anti-CD87 $\mathrm{mAb}$ would need to be continuously present throughout the chemotaxis assay in order to bind to newly expressed CD87 on the cell surface and thereby suppress chemotaxis. Therefore, we performed the assays using PMNs that had been preincubated with the anti-CD87 $\mathrm{mAb}$ as previously described, but washed and resuspended in fresh medium prior to assay. Removing the unbound anti-CD87 $\mathrm{mAb}$ prior to loading into the chemotaxis chambers completely ablated the effect of the anti-CD87 Ab treatment for both FMLP and IL-8 chemotaxis (105.0 and $87.5 \%$ of untreated controls, respectively). Thus, a continuous, saturating supply of anti$\mathrm{CD} 87 \mathrm{mAb}$ is required to inhibit PMN chemotaxis, consistent with the requirement for binding of anti-CD87 $\mathrm{mAb}$ to most, if not all, of the cell surface CD87 for its optimal suppressive effect.

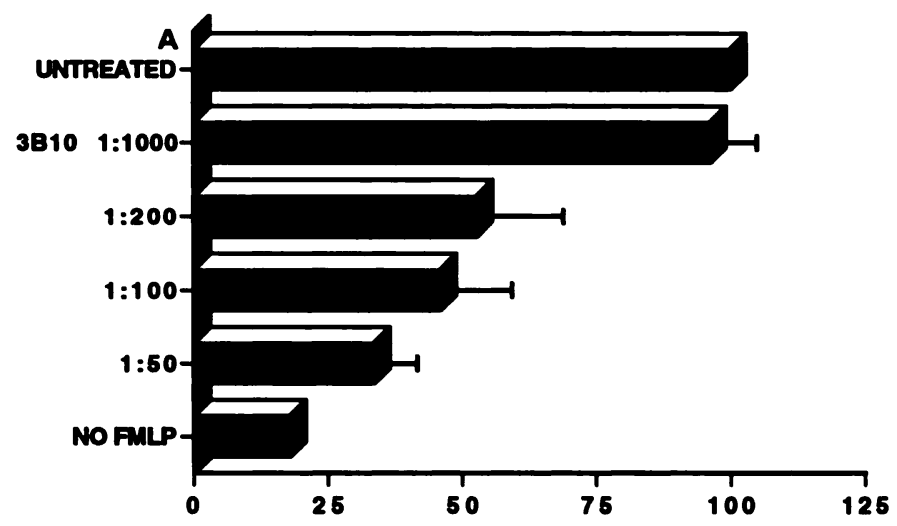

To determine whether the anti-CD87 $\mathrm{mAb}$ had some confounding effect on the chemotaxins themselves, experiments were performed with a 1:50 dilution of the anti-CD87 $\mathrm{mAb}$ placed in the lower chamber along with the chemotaxin. The presence of the anti-CD87 $\mathrm{mAb}$ in the lower chamber had no effect on cell migration induced by either fMLP or IL-8 (101 and $107 \%$ of untreated controls, respectively). Thus the anti-CD87 $\mathrm{mAb}$ did not effect the chemotaxins directly.

Finally, a dose-response relationship was established between the concentration of anti-CD87 $\mathrm{mAb}$ and the suppression of chemotaxis. Dose-related suppression of fMLP-induced chemotaxis could be detected at dilutions ranging from 1:200 to 1:50 (Figure 3A). A similar doseresponse curve was seen for suppression of IL-8-induced chemotaxis (Figure 3B). To provide reference values, random cell movement values are shown and not subtracted from other results as background.

\section{Effects of saccharides on PMN chemotaxis}

Because CD87 is connected to the PMN plasma membrane by a glycosylphosphotidylinositol linkage and therefore lacks a transmembrane domain, there is no straightforward mechanism for transducing signal directly to the cell interior. A potential mechanism by which CD87 may influence PMN function is by collaborating with a partner protein that does possess a transmembrane domain. CD87 has been shown to associate physically with CR3 (CDIlb/CD18, Mac-1, $\alpha_{M} / \beta_{2}$ ) on the neutrophil plasma membrane [23]. CR3 is an attractive candidate for a CD87 partner protein because it is a receptor recognized to be significantly involved in leukocyte adhesion and migration. The association between CD87 and CR3 in PMNs appears to be mediated by interactions of carbohydrate-lectin type because it can be disrupted by specific saccharides [23]. We reasoned that if collaboration between CD87 and CR3 was required for PMN chemotaxis, the same saccharides that disrupt CD87-CR3 colocalization should also inhibit chemotaxis. To test this hypothesis, PMNs were purified and resuspended in medium in the presence and absence of three saccharides previously shown to disrupt CD87-

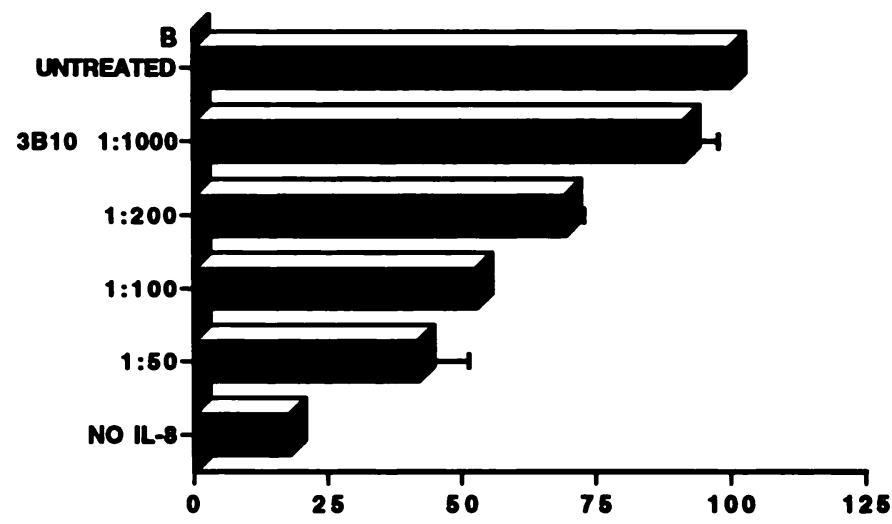

Fig. 3. Dose-related suppression of PMN chemotaxis by anti-CD87 mAb. (A) fMLP-induced chemotaxis. (B) IL-8-induced chemotaxis. Data (number of cells/HPF) are expressed as a percentage of untreated cells, $n=2$. 


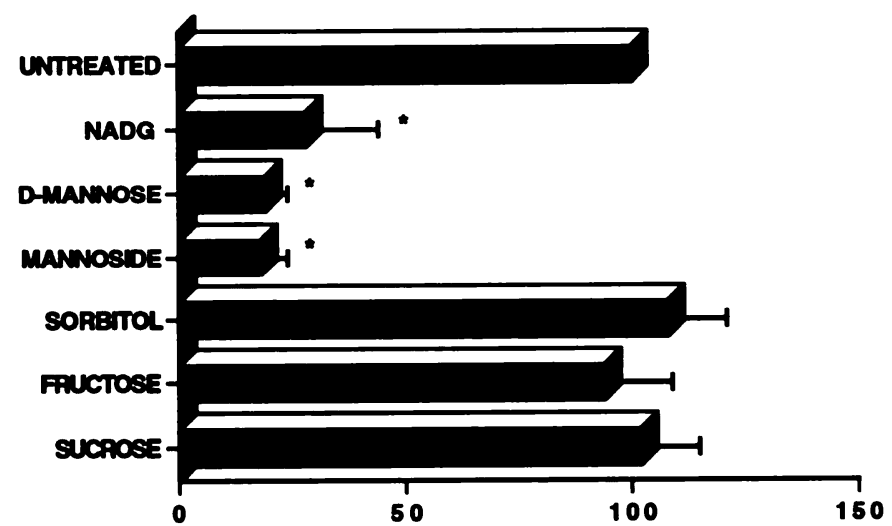

Fig. 4. Specific saccharide inhibition of MLP-induced PMN chemotaxis. Data (number of cells/HPF minus background migration) are expressed as a percentage of untreated cells. ${ }^{*} P<.010, n=6$.

CR3 cocapping (NADG, D-mannose, mannoside) or three control saccharides that have no effect on CD87-CR3 cocapping (sorbitol, fructose, sucrose). All saccharides were used at $100 \mathrm{mM}$. As shown in Figure 4, PMN chemotaxis was dramatically inhibited by NADG, D-mannose, and mannoside $(28 \pm 16,19 \pm 5,18 \pm 6 \%$ of control, respectively; $P<.010)$, but was unaffected by the control saccharides sorbitol, fructose, and sucrose $(108 \pm 13,94 \pm 15,102 \pm$ $13 \%$ of control; $P=\mathrm{NS}$ ). These findings suggest that a carbohydrate-lectin-based association between CD87 and CR3 may be required for PMN chemotaxis. To exclude the possibility that the inhibiting saccharides were interfering with AMLP binding to its receptor, we included control experiments to assess cell surface binding of FL-FNLPNTL (a fluorescein conjugate recognized by the fMLP receptor). PMNs were stained with FL-FNLPNTL in the presence and absence of $100 \mathrm{mM}$ NADG, and FL-FNLPNTL binding was quantitated by fluorescence intensity determined by cytometry, as described previously [24]. The presence of NADG had no effect on the amount of FL-FNLPNTL bound to the cell surface (data not shown). Thus, NADG-induced diminution of chemotaxis cannot be explained by reduced binding of the chemotaxin.

\section{DISCUSSION}

We have established that plasma membrane CD87 serves an obligate function in PMN chemotaxis. The 3B10 antiCD87 mAb dramatically suppresses chemotaxis induced by either fMLP or IL-8, to approximately 26 and $32 \%$ of values for untreated cells, respectively. This effect was not mediated by suppression of CD87-associated uPA enzyme activity, because blocking the active site of receptor-bound uPA had no effect on chemotaxis. Furthermore, saturating the cell surface with catalytically active HMW-uPA had no effect on chemotaxis. These observations extend our prior work demonstrating that CD87 expression is essential for monocyte chemotaxis in response to $\mathrm{MLP}$ or MCP-1 under matrix-free conditions [17]. The anti-CD87 $\mathrm{mAb}$ sup- presses chemotaxis in a dose-related fashion without regard to the chemotaxin used. This effect cannot be explained by either a direct interaction with the chemotaxin or a nonspecific effect of exogenous immunoglobulin.

The anti-CD87 mAb must be present continuously during the assay period in order to suppress PMN chemotaxis. Washing the cells after pretreatment with the anti-CD87 $\mathrm{mAb}$ completely negates the antibody effect. This is consistent with the observation that PMNs contain a substantial intracellular pool of CD87 that can be translocated rapidly to the plasma membrane upon exposure to fMLP [12]. Continuous replenishment of CD87 on the cell surface during chemotaxis would explain why the mAb must be present continuously, because mAb must be available to bind to newly mobilized CD87. This also suggests that most, if not all, of the plasma membrane CD87 must be bound by $\mathrm{mAb}$ to suppress chemotaxis.

Although uPA catalytic activity does not appear to be important in this matrix-free system, it is likely that CD87associated uPA activity is important for extravasation of PMNs in vivo, where degradation of ECM proteins is likely to be required. Plasmin and uPA can degrade extracellular matrix glycoproteins, proteoglycans, and adhesion proteins as well as facilitate destruction of collagen and elastin by activating latent matrix metalloproteinases [6, 25-27]. Monocytes require pericellular uPA activity to penetrate stromal barriers in vitro [28].

The present study was designed to focus on the potential roles of uPA and CD87 in cellular locomotion per se, rather than their conventional roles in regulating proteolytic interactions with ECM proteins. Several intriguing findings have previously linked the expression of CD87 to cell movement. CD87 is known to colocalize with vinculin, alpha actinin, and actin at contact sites with ECM, and CD87 clusters to the leading edge of migration in monocytes when these cells are exposed to a chemotaxin $[15,17]$. Transfecting CD87 into epidermal cells increases directed migration [29]. Collectively, these data suggest that CD87 may provide a dynamic link between ECM proteins and the intracellular machinery of locomotion during cell movement.

The mechanisms by which CD87 critically influences the signaling necessary for chemotaxis remain to be elucidated. In some systems, during cellular locomotion uPA itself may trigger signal transduction through CD87. Cell migration is enhanced when uPA binds to CD87, and monocyte chemotaxis is mildly diminished by blocking uPA expression with antisense oligonucleotide [17, 29].

CD87 is linked to the plasma membrane by a glycosylphosphatidylinositol (GPI) anchor and does not contain a membrane-spanning domain [21, 30]. One of the mechanisms by which GPI-linked proteins can initiate signaling is by conjugating with partner proteins containing a transmembrane domain. Partner protein interactions have been suggested for other GPI-linked molecules, including CD59, CD55, and the ciliary neurotrophic factor receptor [31-33]. Preliminary identification of several candidate partner proteins for CD87 has been achieved. It has been demonstrated that CD87 associates with a $38-k d$ partner protein 
that is tyrosine phosphorylated when uPA is bound to CD87 [34]. Partner protein associations involving CD87 may be cell type specific. In epithelial cell lines, but not in HL-60 cells, uPA-stimulated CD87 associates with two proteins (47 and $55 \mathrm{kd}$ ) both phosphorylated on serine residues [35].

CD87 has been shown to colocalize with the $\beta_{2}$ integrin CR3 on neutrophil plasma membranes $[23,36]$. It is well established that CR3 expression is required for normal cell adhesion and chemotaxis and for functions related to chemotaxis such as phagocytosis $[37,38]$. The coupling of CD87 and CR3 appears to regulate some PMN signaling events. uPA-elicited increases in PMN cytosolic calcium levels require expression of both CD87 and CR3. Such increases in intracellular calcium on binding of uPA to CD87 were absent in PMNs from a patient with leukocyte adhesion deficiency (lacking CR3) and were inhibited by Abs to either CD87 or CR3. Further, incubating PMNs with intact UPA primes the cells for superoxide production [39]. The physical association between CD87 and CR3 can be disrupted by the presence of specific saccharides, suggesting that CD87 and CR3 interact via carbohydrate-lectinlike interactions [23]. This putative mechanism of interaction is quite plausible because CD87 is a heavily glycosylated GPI-linked protein and can thus interact with CR3's lectin-like binding sites $[21,40]$.

Collaboration between CD87 and CR3 provides a potential mechanism by which CD87 could modulate cellular activities previously defined in terms of CR3 functions, including adhesion and directional migration. We have shown that CD87 facilitates the adhesive function of CR3 in monocytes, as blocking CD87 with $\mathrm{mAbs}$ or with antisense oligonucleotides diminishes monocyte adherence to CR3 counterligands. In contrast, the anti-CD87 $\mathrm{mAb}$ had no effect on monocyte adhesion to the $\beta_{1}$ counterligand fibronectin ([41] and R.G. Sitrin et al., manuscript submitted). This work provides further evidence that collaboration between CD87 and CR3 is functionally important.

We reasoned that if the association between CD87 and CR3 was required for normal cellular motility to occur, the same saccharides that disrupt the association between CD87 and CR3 should also inhibit PMN chemotaxis. In order to assess this possibility, we performed chemotaxis assays in the presence of NADG, D-mannose, or $\alpha$-methylmannoside, saccharides previously shown to disrupt CR3 interactions with CD87 [23, 36]. Neutrophil chemotaxis was significantly inhibited in the presence of these disrupting saccharides but was not inhibited in equimolar concentrations of the control saccharides sorbitol, fructose, and sucrose. These data support the hypothesis that CD87 and CR3 associate via carbohydrate-lectin interactions and that disruption of these interactions with specific saccharides inhibits chemotaxis. It is of interest that the same saccharides disrupt the association between CR3 and CD16 (another GPI-linked receptor) [42]. This suggests that carbohydrate-lectin interactions may be of general importance for partner protein and GPI-linked receptor associations. It is possible that both CR3 and CD87 associate with a variety of signaling partner proteins during the complex and highly interdependent events that control cell activation, adherence, and motility.

In summary, we have demonstrated that CD87 has an obligate role in PMN chemotaxis in vitro and that this function is independent of associated uPA enzymatic activity. We provide evidence that carbohydrate-lectin interactions of the type causing CD87/CR3 coupling may play a critical role in chemotaxis. By its integral role in the machinery of cellular locomotion and its capacity to focus uPA and plasmin activities to the pericellular space, CD87 performs two vital and distinct functions in the directional migration of inflammatory cells. These findings substantially expand the importance of CD87 in leukocyte biology beyond its previously established roles in anchoring uPA ectoenzyme activity and its ability to transmit differentiation signals in myeloid cell lines.

\section{ACKNOWLEDGMENTS}

This work was supported by a Veterans Affairs Merit Research Grant (M.R. Gyetko) and NIH Grants HL39672 (R.G. Sitrin) and CA42246 and CA39064 (R.F. Todd III).

\section{REFERENCES}

1. Wilkinson, P., Haston, W. (1988) Chemotaxis: an overview. Methods Enzymol. 162, 3-16.

2. Lauffenburger, D. (1991) Models for receptor-mediated cell phenomena: adhesion and migration. Annu. Rev. Biophys. Chem. 20, 387-414.

3. Danø, K., Andreasen, P.A., Grøndahl-Hansen, J., Kristensen, P., Nielsen, L.S., Skriver, L. (1985) Plasminogen activators, tissue degradation, and cancer. Adv. Cancer Res. 44, 139-266.

4. Huber, A.R., Ellis, S., Johnson, K.J., Dixit, V.M., Varani, J. (1992) Monocyte diapedesis through an in vitro vessel wall construct: inhibition with monoclonal antibodies to thrombospondin. J. Leukoc. Biol. 52, 524-528.

5. Kirchheimer, J.C., Remold, H.C. (1989) Endogenous receptor-bound urokinase mediates tissue invasion of human monocytes. J. Immunol. 143 , $2634-2639$.

6. Liotta, L.A., Goldfarb, R.H., Brundange, R., Siegal, G.P., Terranova, V. Garbisa, S. (1981) Effect of plasminogen activator (urokinase), plasmin, and thrombin on glycoprotein and collagenous components of basement membrane. Cancer Res. 41, 4629-4636.

7. Vassalli, J., Sappino, A., Belin, D. (1991) The plasminogen activator/plasmin system. J. Clin. Invest. 88, 1067-1072.

8. Estreicher, A., Mühlhause, J., Carpentier, J., Orci, L., Vassalli, J. (1990) The receptor for urokinase type plasminogen activator polarizes expression of the protease to the leading edge of migrating monocytes and promotes degradation of enzyme inhibitor complexes. J. Cell Biol. 111, 783-792.

9. Senior, R., Shapiro, S. (1992) Introduction: the matrix metalloproteinase family. Am. J. Respir. Cell. Mol. Biol. 7, 119-127.

10. Werb, Z., Mainardi, C.L., Vater, C.A., Harris, E.D. (1977) Endogenous activation of latent collagenase by synovial cells: evidence for a role for plasminogen activator. N. Engl. J. Med. 296, 1017-1021.

11. Bruckner, A., Filderman, A.E., Kirchheimer, J.C., Binder, B.R., Remold, H.G. (1992) Endogenous receptor-bound urokinase mediates tissue invasion of the human lung carcinoma cell lines A549 and Calu-1. Cancer Res. 52, 3043-3047.

12. Plesner, T., Ploug, M., Ellis, V., Ronne, E., Høyer-Hansen, G., Wittrup, M., Pedersen, T.L., Tscherning, T., Danø, K., Hansen, N.E. (1994) The receptor for urokinase-type plasminogen activator and urokinase is translocated from two distinct intracellular compartments to the plasma membrane on stimulation of human neutrophils. Blood 83, 808-815.

13. Ciambrone, G.J., McKeown-Longos, P.J. (1992) Vitronectin regulates the synthesis and localization of urokinase-type plasminogen activator in HT1080 cells. J. Biol. Chem. 267, 13617-13622.

14. Pollanen, J., Hedman, K., Nielsen, L.S., Dano, K., Vaheri, A. (1988) Ultrastructural localization of plasma membrane-associated urokinase-type plasminogen activator at focal contacts. J. Cell Biol. 106, 87-95.

15. Takahashi, K., Ikeo, K., Gojobori, T., Tanifuji, M. (1990) Local function of 
urokinase receptor at the adhesion contact sites of a metastatic tumor cell. Thromb. Res. [Suppl.] X, 55-61.

16. Pepper, M.S., Sappino, A.P., Stocklin, R., Montesano, R., Orci, L., Vassalli, J.D. (1993) Upregulation of urokinase receptor expression on migrating endothelial cells. J. Cell Biol. 122, 673-683.

17. Gyetko, M.R., Todd, R.F., III, Wilkinson, C.C., Sitrin, R.G. (1994) The urokinase receptor is required for human monocyte chemotaxis in vitro. $J$. Clin. Invest. 93, 1380-1387.

18. Kramer, M.D., Vettel, U., Schmitt, M., Reinartz, J., Brunner, G., Meissauer, A. (1993) Monoclonal antibodies against plasminogen activators and plasmin(ogen). Fibrinolysis 6, 103-111.

19. Mizukami, I.F., Gami-Wagner, B.A., DeAngelo, L.M., Liebert, M., Flint, A. Lawrence, D.A., Cohen, R.L., Todd, R.F., III (1994) Immunologic detection of the cellular receptor for the urokinase plasminogen activator. Clin. Immunol. Immunopathol. 71, 96-104.

20. Min, H., Semnani, R., Mizukami, I., Watt, K., Todd, R.F., III, Liu, D. (1992) cDNA for Mo3, a monocyte activation antigen, encodes the human receptor for urokinase plasminogen activator. J. Immunol. 148, 3636-3642.

21. Mizukami, I., Vinjamuri, S., Trochelman, R., Todd, R.F., III (1990) A structural characterization of the Mo3 activation antigen expressed on the plasma membrane of human mononuclear phagocytes. J. Immunol. 144, 1841-1848.

22. Zar, J.H. (1984) Biostatistical Analysis. Prentice-Hall, Englewood Cliffs, NJ, 121-129.

23. Xue, W., Kindzelskii, A.L., Todd, R.F., III, Petty, H.R. (1994) Physical association of complement receptor type 3 and urokinase-type plasminogen activator receptor in neutrophil membranes. J. Immunol. 152, 4630-4640.

24. Kindzelskii, A.L., Xue, W., Todd, R.F.I., Petty, H.R. (1995) Imaging the spatial distribution of membrane receptors during neutrophil phagocytosis. $J$. Struct. Biol. 113, 191-198.

25. Murphy, G., Doherty, A. (1992) The matrix metalloproteinases and their regulation. Am. J. Respir. Cell. Mol. Biol. 7, 120-125.

26. Chapman, H.A., Stone, O.L., Vavrin, Z. (1984) Degradation of fibrin and elastin by intact human alveolar macrophages in vitro. J. Clin. Invest. 73, 806-815.

27. Mochan, E., Keler, T. (1984) Plasmin degradation of cartilage proteoglycan. Biochim. Biophys. Acta 800, 312-315.

28. Kirchheimer, J.C., Remold, H.C. (1989) Functional characteristics of receptor-bound urokinase on human monocytes: catalytic efficiency and susceptibility to inactivation by plasminogen activator inhibitors. Blood 74, 1396-1402.

29. Del Roseo, M., Anichini, E., Pedersen, N., Blasi, F., Fibbi, G., Pucci, M., Ruggiero, M. (1993) Urokinase-urokinase receptor interaction: non-mitogenic signal transduction in human epidermal cells. Biochem. Biophys. Res. Commun. 190, 347-352.
30. Ploug, M., Ronne, E., Behrendt, N., Jensen, A., Blasi, F., Danø, K. (1991) Cellular receptor for urokinase plasminogen activator carboxyl-terminal processing and membrane anchoring by glycosyl-phosphatidylinositol. J. Biol. Chem. 266, 1926-1933.

31. Stefanova, I., Horejsi, V. (1991) Association of the CD59 and CD55 cell surface glycoproteins with other membrane molecules. J. Immunol. 147, 1587-1592.

32. Stefanova, I., Horejsi, V., Ansotegui, I.J., Knapp, W., Stockinger, H. (1991) GPI-anchored cell-surface molecules complexed to protein tyrosine kinases. Science 254, 1016-1018.

33. Davis, S., Aldrich, T.H., Valenzuela, D.M., Wong, V., Furth, M.E., Squinto, S.P., Yancopoulos, G.D. (1991) The receptor for ciliary neurotrophic factor. Science 253, 59-63.

34. Dumler, I., Petri, T., Schleuning, W.D. (1993) Interaction of urokinase-type plasminogen activator (U-PA) with its cellular receptor (UPAR) induces phosphorylation on tyrosine of a $38 \mathrm{kDa}$ protein. FEBS Lett. 322, 37-40.

35. Busso, N., Masur, S.K., Lazega, D., Waxman, S., Ossowski, L. (1994) Induction of cell migration by pro-urokinase binding to its receptor: possible mechanism for signal transduction in human epithelial cells. J. Cell Biol. 126, 259-270.

36. Petty, H.R., Todd, R.F., III (1993) Receptor-receptor interactions of complement receptor type 3 in neutrophil membranes. J. Leukoc. Biol. 54, 492-494.

37. Kimura, M., Griffin, F.M. (1992) C3bi/Cr3 is a main ligand-receptor interaction in attachment and phagocytosis of C3-coated particles by mouse peritoneal macrophages. Scand. J. Immunol. 36, 183-191.

38. Wallis, W.J., Beatty, P.G., Ochs, H.D., Harlan, J.M. (1985) Human monocyte adherence to cultured vascular endothelium: monoclonal antibody-defined mechanisms. J. Immunol. 135, 2323-2330.

39. Cao, D., Mizukami, I.F., Garni-Wagner, B.A., Kindzelskii, A.L., Todd, R.F. III, Boxer, L.A., Petty, H.R. (1995) Human urokinase-type plasminogen activator primes neutrophils for superoxide anion release. J. Immunol. 154, 1817-1829.

40. Ross, G.D., Cain, J.A., Lachmann, P.J. (1985) Membrane complement receptor type three (CR3) has lectin-like properties analogous to bovine conglutinin and functions as a receptor for zymosan and rabbit erythocytes as well as a receptor for CR3. J. Immunol. 134, 3307.

41. Gyetko, M.R., Shollenger, S.B., Todd, R.F., III, Sitrin, R.G. (1994) Urokinase receptors facilitate $\mathrm{CD} 1 \mathrm{lb} / \mathrm{CD} 18$-mediated adhesion of human monocytes. Am. J. Resp. Crit. Care 151, A340.

42. Zhou, M.-J., Todd, R.F., III, van de Winkel, J.J.G.J., Petty, H.R. (1993) Cocapping of the leukoadhesion molecules complement receptor type 3 and lymphocyte function-associated antigen-l with Fc $\gamma$ receptor III on human neutrophils. J. Immunol. 150, 3030-3041. 